\title{
State and status of physical education in tertiary institutions in selected European countries in the second decade of the $21^{\text {st }}$ century
}

\author{
Robert Podstawski ${ }^{1 凶}$, Marta Żurawik², Krzysztof Borysławski ${ }^{3}$, Alena Bukova ${ }^{4}$, Bojan Masanovic ${ }^{5}$, Zoltán Alföldi ${ }^{6}$, \\ and Piotr Żurek \\ ${ }^{1}$ Department of Tourism, Recreation and Ecology, Faculty of Geoengineering, University of Warmia and Mazury in Olsztyn, Olsztyn, \\ Poland; ' 2 Independent Researcher, Wigan, United Kingdom; ${ }^{3}$ Department of Anthropology, Wrocław University of Environmental \\ and Life Sciences, Wroclaw, Poland; ${ }^{4}$ Institute of Physical Education and Sport, Pavol Jozef Šafárik University in Košice, Košice, Slovak \\ Republic; ${ }^{5}$ Faculty for Sport and Physical Education, University of Montenegro, Nikšić, Montenegro; ${ }^{6}$ Faculty of Health Sciences, Uni- \\ versity of Pécs, Pécs, Hungary; and ${ }^{7}$ Department of Physical Education, University of Physical Education in Poznan, Poznan, Poland
}

\begin{abstract}
Background: For the majority of students, the transition into higher education seems to have deleterious effects on their physical activity (PA) behaviors and motivation. To tackle students' physical inactivity, reforms in higher education were supposed to reinvent physical education (PE) programs, revise their objectives and tasks. Nevertheless, European universities are experiencing a physical activity crisis, and recent generations of students are facing health problems due to underprovided levels of PA. Objective: The aim of this descriptive study was to analyze the state and status of physical education in higher education in selected European countries with regards to its curriculum and resources. Methods: Quantitative data were collected from 66 tertiary institutions from various countries in Europe. The questionnaire was used to gather information regarding characteristics of tertiary institutions, sport and leisure facilities, types and characteristics of PA programs available for students. Results: PE classes were obligatory in $44 \%$ and facultative in $30.3 \%$ of tertiary institutions; $22.7 \%$ of the institutions offered mixed PE curricula. The most popular team sports were volleyball, soccer and basketball, whereas fitness and functional training were the most popular types of individual PA. PE sessions lasted one or two semesters in $53 \%$ of the institutions. In $12 \%$ of establishments, PE was not part of curricula. In $60 \%$ of institutions, PE curricula consisted of 31-60 academic hours during the entire study program, and 55\% of establishments charged additional fees for sports activities. In 55\% of the analyzed institutions, physical fitness assessments were conducted only to determine students' eligibility to participate in team sports. Conclusions: The research study investigated problems of insufficient PA levels in higher education, indicating several reasons for this state of affairs. The study recommends that PE curricula are thoughtfully planned and executed with improved financing. Furthermore, PE ought to be combined with health education to promote active and healthy lifestyles among students.
\end{abstract}

Keywords: higher education, post-secondary education, fitness, conditions, evaluation

\section{Introduction}

Regular participation in physical activity (PA) is an important contributor to a healthy lifestyle, including for university and college students (UCS), and it can provide immediate and future health benefits (Hilland et al., 2009). Physical activity can improve young adults' psychological well-being and promote moral reasoning, positive self-concepts, and social interaction skills (Bunker, 1998). In recognition of these health benefits, PA guidelines have been developed to encourage participation, and the main recommendation is that young adults engage in at least $60 \mathrm{~min}$ of moderate to vigorous PA every day (Garber et al., 2011). The minimum recommended amount of PA for individuals aged 18 to 65 is $\geq 30 \mathrm{~min} /$ day of moderate-intensity endurance training performed 5 days per week ( $\geq 150 \mathrm{~min} /$ week) or $\geq 25 \mathrm{~min}$ of high-intensity endurance training performed 3 days per week ( $\geq 75 \mathrm{~min} /$ week). Resistance, balance, agility and coordination training targeting each muscle group is recommended 2-3 days per week, and stretching exercises (60 s) are recommended 2 days per week (Garber et al., 2011; Haskell et al., 2007).

Current evidence clearly suggests that many UCS in various countries, including Hungary, Slovakia, Czech Republic, Poland, Romania and Spain, do not meet the above recommendations in the process of transitioning from adolescence to adulthood (Fagaras et al., 2015; Hujova, 2013; Kaj et al., 2015; Martínez-Lemos et al., 2014; Podstawski et al., 2014; Sigmundová et al., 2013). Bray and Born (2004)

\footnotetext{
$\triangle$ Corresponding author: Robert Podstawski, e-mail podstawskirobert@gmail.com, ORCID ${ }^{\circledR}$ record https://orcid.org/0000-0002-1492-252X Article history: Received January 20 2021, Accepted June 8 2021, Published July 142021

Copyright: (c) 2021 The Author(s). Published by Palacký University Olomouc. This is an open access article distributed under the terms of the Creative Commons Attribution License (https://creativecommons.org/licenses/by/4.0/), which permits unrestricted use, distribution, and reproduction in any medium, provided the original author and source are credited. This license does not cover any third-party material that may appear with permission in the article.
} 
reported that one-third of students who were active in high school became insufficiently active upon transitioning to university life. In turn, the Youth Risk Behavior Survey (Kann et al., 1996) demonstrated that $55 \%$ of high school seniors have adequate PA levels, whereas less than $40 \%$ of UCS meet the recommended standard (Douglas et al., 1997). University students who begin to live independently experience changes in lifestyle habits, attitudes and social roles (Li et al., 2009). The transition process seems to have deleterious effects on their PA behavior and motivation, which lead to a significant decline in the students' PA levels (Kwan et al., 2012; Podstawski, Wesołowska, et al., 2013), predominantly among women (Fagaras et al., 2015; Zhao et al., 2007). In Europe, low PA levels were reported among Romanian (Fagaras et al., 2015), Polish (Podstawski et al., 2014) and Spanish students (Martínez-Lemos et al., 2014; Varela-Mato et al., 2012). According to Corbin (2002) and Keating et al. (2005), low PA levels have been identified as one of the six priority health risks in student populations, which call for immediate action.

Reforms in higher education were expected to reinvent tertiary institutions, revise their objectives and tasks, and effectively improve the PA levels of academic youths (Muszkieta et al., 2019). The purpose of higher education is to produce active and intellectually well-rounded individuals who possess the knowledge and skills for continued personal growth, including in the area of PA and health promotion. In addition to knowledge, physical education (PE) is essential for instilling attitudes, motivations and behaviors that contribute to a healthy lifestyle. Nevertheless, research indicates that universities are experiencing a physical activity crisis, and the recent generation of graduates is characterized by very low PA levels.

Studies exploring the PA levels of UCS are particularly vital since PE is no longer a mandatory subject during tertiary education in most countries of the world (Cardinal et al., 2012; Hardman, 2008; Lipošek et al., 2018). Therefore, the purpose of this study is to determine the status of PE curricula of higher education in selected European countries. The study aims to review selected aspects of PE in tertiary institutions in Europe, with specific reference to status, curriculum (time allocation, aims and content) and resources (facilities and equipment). The study was undertaken to challenge the existing status of PE in tertiary institutions, recommend directions for a sustainable and secure future of PE in higher education as a lifestyle-enhancing activity.

\section{Methods}

Instrument and procedures

The research was carried out upon the prior consent of the Ethical Committee of the University of Warmia and Mazury in Olsztyn, Poland (No. 39/2011).

The descriptive research employed the quantitative approach to data collection in order to provide a numeric description of the research population. The strength of the quantitative approach lies in collecting structured quantifiable data from a collection of institutions. In addition, the quantitative method allows information to be measured and compared. A purposive sampling method was employed and involved selecting people to produce the most valuable data for the research purpose. Therefore, an invitation for a research collaboration was issued to all academics attending the $16^{\text {th }}$ Annual Scientific Conference of Montenegrin Sports Academy entitled "Sport, Physical Activity and Health: Contemporary Perspectives" in Dubrovnik, Croatia. Furthermore, academic peers who worked in various European research and teaching centres were contacted via the ResearchGate.net platform. Forty-seven academics who agreed to participate in the study were required to answer all questions concerning PA programs from at least 10 European tertiary institutions by the end of February 2020. All respondents were informed that participation was voluntary, and withdrawal was allowed at any time.

\section{Self-administered questionnaire}

The quantitative data were collected using anonymous and confidential questionnaires, which had the same set of written questions in English in a predetermined order. The aim of the questionnaires was to investigate the state and status of physical education in higher education in selected European countries with regards to its curriculum and resources.

The questionnaires included 16 closed-ended questions and two open-ended questions concerning: (1) characteristics of tertiary institutions, (2) sport facilities, (3) types of PA programs available for students, and (4) characteristics of PA sessions.

The process of sending the questionnaires was supervised by the researchers and supported by the research participants who agreed to contribute to the research and obtain results from at least nine institutions. The questionnaires were sent in pdf form via e-mails to the heads of units responsible for $\mathrm{PE}$ programs at the tertiary institutions (e.g., Departments of Physical Education and Sport, Centres of Sport and Recreation).

In total, out of forty-seven initial participants, only seven academic peers completed and returned the questionnaires within the required timeframe. Based on the answers, the researchers created a database in Microsoft Excel, which included information from 66 tertiary institutions hosting 798,181 students, located in various countries across Europe.

\section{Data analysis}

Descriptive analysis was conducted. Data were analysed with emphasis on types of tertiary institutions (public vs. private and universities vs. other institutions). Data in the text are given as means \pm standard deviations.

\section{Results}

\section{Characteristics of the surveyed universities}

A total of 66 tertiary establishments were surveyed, including Poland (45.4\%), Slovakia (18.2\%), Czech Republic (7.6\%), Hungary (9.1\%), Serbia (9.1\%), Bosnia-Herzegovina $(1.5 \%)$, Croatia (1.5\%), Kosovo (1.5\%), Montenegro $(1.5 \%)$, Slovenia (1.5\%), Spain (1.5\%), and Turkey (1.5\%). Forty-five $(68.2 \%)$ of the analyzed institutions 
were situated in cities with a population between 59,000 and 500,000 . The majority $(88.3 \%)$ of establishments had a public status. Forty-six (69.7\%) of the institutions were universities. In terms of enrollment, half of the institutions hosted between 5,000 and 20,000 students. A detailed analysis of the characteristics of the tertiary institutions is presented in Table 1.

The tertiary institutions were located in cities with a population range between 59,000 and 2.5 million, with a mean of 12,094 students per institution. Fifty-eight universities offered PE programs. On average, students attended PE classes for 3.1 semesters during their entire study program, which means 28.4 academic hours per semester and 67.9 academic hours during the entire study program. PE programs consisted of 15 sessions per semester, which were around $45.69 \mathrm{~min}$ per academic hour and $89 \mathrm{~min}$ per session (Table 2).

\section{PE curricula}

PE was obligatory in 29 universities (44\%), as a facultative subject in 20 (30.3\%) institutions, whereas 15 (22.7\%) universities offered a mixture of obligatory/facultative PE programs. In 46 (69.7\%), institutions, students were able to select the preferred type of PA, which were mostly team sports (57.6\%) or standard PE classes (42.4\%). In half of the establishments, PE programs were conducted for one to two semesters. Eight universities had no PE programs. The number of academic hours (i.e., $45 \mathrm{~min}$ ) dedicated to PE during the entire study program was between 31 and 60 hours in 39 (59.1\%) institutions. Thirty-five universities $(54.5 \%)$ charged additional fees for PA programs. PE students were graded for their performance in $50(76.9 \%)$ establishments and received credits in 11 (16.9\%) institutions. The grading system was developed by academic staff and included attendance and tardiness in 61 (92\%) institutions, motivation and attitude in 47 (71.6\%) institutions. Fitness levels and motor abilities were evaluated only to determine students' eligibility to participate in sports teams (in $57.6 \%$ and $56.1 \%$ of the institutions, respectively). Detailed analysis is presented in Table 3.

\section{PE facilities and sports infrastructure}

The majority of PE facilities were classified as good (45.5\%), very good $(24.2 \%)$. The most common sports facilities available for students were fitness gyms (95.5\%), indoor courts for team sports $(90.9 \%)$ and pool-spa centers $(86.4 \%)$. The most popular PA sessions offered by the tertiary institutions were volleyball (99.4\%), fitness classes (90.9\%), basketball (83.3\%), functional training (80.3\%) and soccer $(78.85 \%)$. Detailed analysis of PE facilities and sports infrastructure is presented in Table 4.

Table 1 Characteristics of the tertiary institutions

\begin{tabular}{|c|c|c|}
\hline & $n$ & $\%$ \\
\hline \multicolumn{3}{|l|}{ Country } \\
\hline Bosnia-Herzegovina & 1 & 1.5 \\
\hline Croatia & 1 & 1.5 \\
\hline Czech Republic & 5 & 7.6 \\
\hline Hungary & 6 & 9.1 \\
\hline Kosovo & 1 & 1.5 \\
\hline Montenegro & 1 & 1.5 \\
\hline Poland & 30 & 45.4 \\
\hline Serbia & 6 & 9.1 \\
\hline Slovakia & 12 & 18.2 \\
\hline Slovenia & 1 & 1.5 \\
\hline Spain & 1 & 1.5 \\
\hline Turkey & 1 & 1.5 \\
\hline \multicolumn{3}{|l|}{ City population (thousands) } \\
\hline $59-500$ & 45 & 68.2 \\
\hline $501-1,000$ & 12 & 18.2 \\
\hline More than 1,000 & 9 & 13.6 \\
\hline \multicolumn{3}{|l|}{ Type of institution } \\
\hline University & 46 & 69.7 \\
\hline College & 9 & 13.6 \\
\hline Polytechnic & 5 & 7.6 \\
\hline Art college & 1 & 1.5 \\
\hline Vocational high school & 1 & 1.5 \\
\hline Teacher training college & 4 & 6.1 \\
\hline \multicolumn{3}{|l|}{ Status } \\
\hline Public & 55 & 88.3 \\
\hline Private & 11 & 16.7 \\
\hline \multicolumn{3}{|c|}{ Number of students (thousands) } \\
\hline Less than 1 & 12 & 18.2 \\
\hline $1-5$ & 8 & 12.1 \\
\hline $5-10$ & 18 & 27.3 \\
\hline $10-20$ & 15 & 22.7 \\
\hline More than 20 & 13 & 19.7 \\
\hline
\end{tabular}

Table 2 Quantitative characteristics of the tertiary institutions

\begin{tabular}{|c|c|c|c|c|}
\hline Feature & $n$ & $M$ & $S D$ & Range \\
\hline City population (thousands) & 66 & 496.88 & 523.37 & $59-2,500$ \\
\hline Number of students & 66 & 12,094 & 13,626 & $21-80,000$ \\
\hline Number of PE hours per semester & 58 & 28.41 & 3.89 & $13-40$ \\
\hline Number of PE hours during the study program & 58 & 67.88 & 43.50 & $13-240$ \\
\hline Duration of one PE session & 58 & 89.05 & 9.25 & $45-120$ \\
\hline Number of PE teachers & 66 & 12.26 & 10.23 & $1-50$ \\
\hline Number of students per teacher & 66 & 1,478 & $2,258.50$ & $1.5-14,000$ \\
\hline
\end{tabular}

Note PE $=$ physical education . 
Table 3 Implementation of PE curricula in the surveyed European tertiary institutions

\begin{tabular}{|c|c|c|}
\hline & $n$ & $\%$ \\
\hline \multicolumn{3}{|c|}{ Is PE a part of the university curriculum? } \\
\hline Yes & 45 & 68.2 \\
\hline No & 5 & 7.6 \\
\hline Only in selected departments & 16 & 24.2 \\
\hline Other PA programs & 17 & 25.8 \\
\hline \multicolumn{3}{|l|}{ How is PE implemented? } \\
\hline Compulsory class & 29 & 44.0 \\
\hline Voluntary & 20 & 30.3 \\
\hline Compulsory or voluntary & 15 & 22.7 \\
\hline \multicolumn{3}{|c|}{ What types of PE curricula are offered? } \\
\hline Standard PE classes & 28 & 42.4 \\
\hline Students select the preferred PA & 46 & 69.7 \\
\hline Sports teams & 38 & 57.6 \\
\hline Lectures & 14 & 21.2 \\
\hline Instructor courses & 12 & 18.2 \\
\hline Participation in sports events & 10 & 15.2 \\
\hline \multicolumn{3}{|c|}{ Number of PE semesters during the study program } \\
\hline No regular PE classes & 8 & 12.1 \\
\hline $1-2$ & 35 & 53.0 \\
\hline $3-4$ & 17 & 25.8 \\
\hline $5-10$ & 6 & 9.1 \\
\hline \multicolumn{3}{|c|}{ Number of PE hours of during the study program } \\
\hline No regular PE classes & 8 & 12.1 \\
\hline Up to 30 & 9 & 13.6 \\
\hline $31-60$ & 39 & 59.1 \\
\hline $61-120$ & 4 & 6.1 \\
\hline More than 120 & 6 & 9.1 \\
\hline \multicolumn{3}{|c|}{ PA programs are available at additional charge } \\
\hline Yes & 35 & 53.0 \\
\hline No & 31 & 47.0 \\
\hline \multicolumn{3}{|l|}{ PA programs are freely available } \\
\hline Yes & 36 & 54.5 \\
\hline No & 30 & 45.5 \\
\hline \multicolumn{3}{|l|}{ Are PE students evaluated? } \\
\hline Students are graded & 50 & 76.9 \\
\hline Students receive credit & 11 & 16.9 \\
\hline Credit is not given for $\mathrm{PE}$ & 4 & 6.2 \\
\hline \multicolumn{3}{|l|}{ Who sets the grading criteria? } \\
\hline Teachers & 66 & 100.0 \\
\hline \multicolumn{3}{|l|}{ Factors that influence grade/credit } \\
\hline Attendance & 61 & 92.4 \\
\hline Tardiness & 61 & 92.4 \\
\hline Motivation & 47 & 71.2 \\
\hline Fitness level - sports teams & 38 & 57.6 \\
\hline Motor skills - sports teams & 37 & 56.1 \\
\hline
\end{tabular}

Note. $\mathrm{PE}=$ physical education; $\mathrm{PA}=$ physical activity
Table 4 Physical education facilities and sports infrastructure

\begin{tabular}{|c|c|c|}
\hline & $n$ & $\%$ \\
\hline \multicolumn{3}{|l|}{ Overall physical education facilities } \\
\hline None & 1 & 1.5 \\
\hline Very poor & 17 & 25.8 \\
\hline Poor & 4 & 6.1 \\
\hline Good & 28 & 45.4 \\
\hline Very good & 16 & 24.2 \\
\hline \multicolumn{3}{|c|}{ Sports infrastructure (at least 1 facility) } \\
\hline Fitness gym & 63 & 95.5 \\
\hline Game court & 60 & 90.9 \\
\hline Pool-spa & 57 & 86.4 \\
\hline Volleyball court & 49 & 74.2 \\
\hline Basketball court & 46 & 69.7 \\
\hline Cardio gym & 42 & 63.6 \\
\hline Tennis court & 35 & 53.0 \\
\hline Soccer field & 30 & 45.5 \\
\hline Athletics stadium & 27 & 40.9 \\
\hline Combat sports - gym/dojo & 26 & 39.4 \\
\hline Jogging \& walking routes & 22 & 33.3 \\
\hline Outdoor gym & 18 & 27.3 \\
\hline Beach volleyball court & 14 & 21.2 \\
\hline Sailing harbor & 9 & 13.6 \\
\hline Street workout facility & 7 & 10.6 \\
\hline Other & 6 & 9.1 \\
\hline Golf course & 5 & 7.6 \\
\hline Equestrian center & 1 & 1.5 \\
\hline Skate park & 1 & 1.5 \\
\hline \multicolumn{3}{|l|}{ Available physical activity types } \\
\hline Fitness, aerobics, spinning & 60 & 90.9 \\
\hline Volleyball & 59 & 89.4 \\
\hline Basketball & 55 & 83.3 \\
\hline Functional training & 53 & 80.3 \\
\hline Football & 52 & 78.8 \\
\hline Swimming & 42 & 63.6 \\
\hline Weight training / powerlifting & 39 & 59.1 \\
\hline Handball & 34 & 51.5 \\
\hline Tennis & 32 & 48.5 \\
\hline Yoga & 30 & 45.5 \\
\hline Table tennis & 30 & 45.5 \\
\hline Winter sports & 27 & 40.9 \\
\hline Cycling & 25 & 37.9 \\
\hline Athletics & 24 & 36.4 \\
\hline Judo & 22 & 33.3 \\
\hline Karate & 21 & 31.8 \\
\hline Aerobics & 19 & 28.8 \\
\hline Callanetics & 19 & 28.8 \\
\hline Kick-boxing & 18 & 27.3 \\
\hline Climbing & 16 & 24.2 \\
\hline Rowing & 15 & 22.7 \\
\hline Horseback riding & 10 & 15.2 \\
\hline Sailing & 10 & 15.2 \\
\hline Golf & 9 & 13.6 \\
\hline Badminton & 8 & 12.1 \\
\hline Chess & 7 & 10.6 \\
\hline Fencing & 4 & 6.1 \\
\hline Floorball & 3 & 4.5 \\
\hline
\end{tabular}




\section{Discussion}

Educational reforms executed by European countries intended to contribute to the development of PE standards at all levels of the educational system (European Education and Culture Executive Agency \& European Education and Culture Executive Agency, 2013). However, the results of the present study indicate that the importance of PE has been steadily declining in higher education in recent decades, since more than $30 \%$ of the analyzed institutions had their PE curricula reduced to a minimum or removed from the study programs. The diminished status of the PE in higher education could be attributed to the budgetary constraints that posed a challenge for nearly all tertiary establishments around the world (Isola, 2017; Valero \& Van Reenen, 2019), which also led the authorities to question the value of PE in higher education (National Association for Sport and Physical Education and American Heart Association, 2006). However, academics argue that the decision to downgrade the importance of PE classes in tertiary education was misguided and irresponsible (Majeric, 2016; Podstawski, 2018; Podstawski \& Sławek, 2016). The supporters of school-based PE curricula have argued that obligatory PE could, at least to some degree, prevent overweight and obesity among university students, enhance fitness and motor skills, as well as improve students' concentration and cognitive functioning (Obama, 2012; Shephard, 1997; Tomporowski, 2003).

In the institutions where PE classes were obligatory, the average of 15 sessions per semester provided around 90 min of PA per week, which is hardly sufficient to meet the students' demand for exercise. In particular, the research showed that in many Polish and Slovakian tertiary institutions students who attended obligatory PE classes very rarely performed any types of extracurricular PA (Bukova et al., 2019; Hujova, 2013; Podstawski et al., 2014; Podstawski, Górnik, \& Gizińska, 2013). Furthermore, studies exploring the lifestyle of university students have demonstrated that only a fraction of students participated in facultative PA organized by tertiary institutions (Majeric, 2016).

The current study also revealed that a few European higher education institutions did not have any PE facilities, a third had poor sports infrastructure and a fifth offered obligatory PE classes in the form of theoretical lectures and assessment. In turn, the tertiary establishments that had adequate facilities did not offer free PA curricula and restricted the scope of PE to team sports. This worrying situation might be caused by high levels of autonomy of the tertiary institutions (Aghion et al., 2010). The status of $\mathrm{PE}$ in various European countries is influenced by different factors, which contribute to the evolution of national educational systems through assimilation or adaptation at the conceptual and practical level (Hardman, 2008). For instance, local sports traditions vary across countries, and the popularity of different sports and types of PA is strongly influenced by regional trends. In the USA, the United Kingdom and other countries, students' athletic performance and achievements, both on and off-campus, considerably influence their reputation and popularity in the academic community. In these countries, ball games (soccer, basketball, volleyball) are strongly rooted in national traditions and are highly popular (Berman, 2019). Furthermore, students are eager to follow new fitness trends, such as functional training, high-intensity interval training and high-intensity circuit training (Klika \& Jordan, 2013; Majeric, 2016; Thompson, 2017). The results of this study indicate that university students were able to select from a wide range of PA offered by the institutions, yet the strong presence of general PE classes that teach and develop physical skills in higher education still seems surprising. This could be due to the fact that most PE guidelines in tertiary institutions are highly general and often sustain the guidelines from secondary education. Furthermore, PE in higher education does not support the assessment of specific PE goals, such as motor, cognitive, affective development, that should be achieved in each stage of the educational process (Derri et al., 2012), which is critical for effective PE teaching and training (Mertler, 2009). Similarly in this study, fitness levels and motor abilities were evaluated only to determine the students' eligibility to participate in team sports. In turn, students attending obligatory PE classes were graded mainly on attendance, attitude and motivation. As motor abilities of university students continue to decline (Kaj et al., 2015; Mleczko \& Januszewski, 2009; Negasheva \& Mishkova, 2005), the fitness assessments should play a crucial role in monitoring and evaluating the quality of PE curricula in higher education. It is important that PE curricula are thoughtfully planned and executed by considering allocating one day of the week to PE combined with health education.

\section{Limitations}

A clear limitation of the present study was the rather small number of other tertiary institutions, such as polytechnics, colleges, pedagogical high schools, higher vocational schools, art schools in the study sample. Another limitation was the fact that the majority of participating tertiary institutions were located in former Eastern Bloc countries where PE was obligatory and intensely promoted during the Communist regime. Furthermore, it must be acknowledged that the representation of the tertiary institutions in different European countries was not uniform. Therefore, it is possible that the presented findings could differ considerably if all EU Member States were represented.

\section{Conclusions}

The research study deals with a very important social problem of insufficient PA of students in higher education since PE has been downgraded in European tertiary education in recent years. The theoretical contribution of this study focused on indicating several reasons for this state of affairs, such as insufficient space for physical education in academic education programs, its relatively low prestige in the academic environment, and deficiencies in the sports infrastructure in many European institutions. In particular, this research also contributes to the in-depth observation of this problem in Central and Eastern Europe. The practical contribution and recommendations of this study focus on 
extending the number and duration of PE classes, which also should become obligatory, and other PA programs should be free and accessible to all students during the entire study program.

This research study recommends there is a need to increase levels of PA in higher education across Europe in order to reduce levels of obesity and health risk associated with a sedentary lifestyle and encourage a healthy and active lifestyle in the long turn. Also, it is recommended that students who attend PE should not be graded on attendance only, and the evaluation should reflect their fitness levels and motor abilities. Furthermore, it is vital that PE curricula are thoughtfully planned and executed by considering extended hours, appropriately qualified teachers and improved financing.

\section{Acknowledgments}

The authors would like to thank the participants for their contribution to the study.

This study was supported by the University of Warmia and Mazury in Olsztyn.

\section{Conflict of interest}

The authors report no conflict of interest.

\section{References}

Aghion, P., Dewatripont, M., Hoxby, C., Mas-Colell, A., \& Sapir, A. (2010). The governance and performance of universities: Evidence from Europe and the US. Economic Policy, 25(61), 7-59. https://doi.org/10.1111/i.1468-0327.2009.00238.x

Berman, M. (2019). Most popular sports among students around the world Sports exemplifies a healthy and active lifestyle. https://programminginsider.com/ most-popular-sports-among-students-around-the-world

Bray, S. R., \& Born, H. A. (2004). Transition to university and vigorous physical activity: Implications for health and psychological well-being. Journal of American College Health, 52(4), 181-188. https://doi.org/10.3200/JACH.52.4.181-188

Bukova, A., Zuskova, K., Szerdiova, L., \& Horbacz, A. D. (2019). Selected lifestyle factors of female university students in the reflection of sports activities. Health Problems of Civilization, 13(1), 38-47. https://doi.org/10.5114/hpc.2019.81109

Bunker, L. K. (1998). Psycho-physiological contributions of physical activity and sports for girls. President's Council on Physical Fitness and Sports Research Digest, 3(2), 1-10. https://files.eric.ed.gov/fulltext/ED418935.pdf

Cardinal, B. J., Sorensen, S. D., \& Cardinal, M. K. (2012). Historical perspective and current status of the physical education graduation requirement at American 4-year colleges and universities. Research Quarterly for Exercise and Sport, 83(4), 503-512. https://doi.org/10.1080/02701367.2012.10599139

Corbin, C. B. (2002). Physical education as an agent of change. Quest, 54(3), 182-195. https://doi.org/10.1080/00336297.2002.10491773

Derri, V., Avgerinos, A., Emmanouilidou, K., \& Kioumourtzoglou, E. (2012). What do Greek physical education teachers know about elementary student assessment? Journal of Human Sport and Exercise, 7(3), 658-670. https://doi. org/10.4100/ihse.2012.73.06

Douglas, K. A., Collins, J. L., Warren, C., Kann, L., Gold, R., Clayton, S., Ross, J. G., \& Kolbe, L. J. (1997). Results from the 1995 National College Health Risk Behavior Survey. Journal of American College Health, 46(2), 55-66. https://doi. org/10.1080/07448489709595589

European Education and Culture Executive Agency \& European Education and Culture Executive Agency. (2013). Physical education and sport at school in Europe. https://doi.org/10.2797/49648

Fagaras, S. P., Radub L. E., \& Vanvuc, G. (2015). The level of physical activity of university students. Procedia - Social and Behavioral Sciences, 197, 14541457. https://doi.org/10.1016/i.sbspro.2015.07.094

Garber, C. E., Blissmer, B., Deschenes, M. R., Franklin, B. A., Lamonte, M. J., Lee, I. M., Nieman, D. C., \& Swain, D. P. (2011). Quantity and quality of exercise for developing and maintaining cardiorespiratory, musculoskeletal, and neuromotor fitness in apparently healthy adults: Guidance for prescribing exercise. Medicine \& Science in Sports \& Exercise, 43(7), 1334-1359. https://doi. org/10.1249/MSS.0b013e318213fefb

Hardman, K. (2008). Situation and sustainability of physical education in schools: A global perspective. Spor Bilimleri Dergisi, 19(1), 1-22. https://dergipark.org.tr/ en/pub/sbd/issue/16392/171417
Haskell, W. L., Lee, I.-M., Pate, R. R., Powell, K. E., Blair, S. N., Franklin, B. A., Macera, C. A., Heath, G. W., Thompson, P. D., \& Bauman, A. (2007). Physical activity and public health: Updated recommendation for adults from the American College of Sports Medicine and the American Heart Association. Medicine \& Science in Sports \& Exercise, 39(8), 1423-1434. https://doi. org/10.1249/mss.0b013e3180616b27

Hilland, T. A., Stratton, G., Vinson, D., \& Fairclough, S. (2009). The physical education predisposition scale: Preliminary development and validation. Journal of Sport Sciences, 27(14), 1555-1563. https://doi.org/10.1080/02640410903147513 Hujova, Z. (2013). The prevalence of obesity and hypertension among first-year students at Trnava University in Slovakia. International Journal of Medicine and Medical Sciences, 5(8), 361-367. https://doi.org/10.5897/IJMMS2013.0925

Isola, F. O. (2017). Socio-economic impact of tertiary institutions in Nigeria on host community. American Journal of Management Science and Engineering, 2(6), 176-182. https://doi.org/10.11648/i.ajmse.20170206.13

Kaj, M., Tékus, É., Juhász, I., Stomp, K., \& Wilhelm, M. (2015). Changes in physical fitness of Hungarian college students in the last fifteen years. Acta Biologica Hungarica, 66(3), 270-281. https://doi.org/10.1556/018.66.2015.3.3

Kann, L., Warren, C. W., Harris, W. A., Collins, J. L., Williams, B. I., Ross, J. G., \& Kolbe, L. J. (1996). Youth risk behavior surveillance - United States, 1995. MRWR CDC Surveillance Summaries, 45(4), 1-84. https://www.cdc.gov/mmwr/ preview/mmwrhtml/00043812.htm

Keating, X. D., Guan, J., Piñero, J. C., \& Bridges, D. M. (2005). A meta-analysis of college students' physical activity behaviors. Journal of American College Health, 54(2), 116-126. https://doi.org/10.3200/JACH.54.2.116-126

Klika, B., \& Jordan, C. (2013). High-intensity circuit training using body weight: Maximum results with minimal investment. ACSM's Health \& Fitness Journal, 17(3), 8-13. https://doi.org/10.1249/FIT.0b013e31828cb1e8

Kwan, M. Y., Cairney, J., Faulkner, G. E., \& Pullenayegum, E. E. (2012). Physical activity and other health-risk behaviours during the transition into early adulthood: A longitudinal cohort study. American Journal of Preventive Medicine, 42(1), 14-20. https://doi.org/10.1016/j.amepre.2011.08.026

Li, K.-K., Cardinal, B. J., \& Settersten, R. A. (2009). A life-course perspective on physical activity promotion: Application and implication. Quest, 61(3), 336352. https://doi.org/10.1080/00336297.2009.10483620

Lipošek, S., Planinšec, J., Leskošek, B., \& Pajtler, A. (2018). Physical activity of university students and its relation to physical fitness and academic success. Annales Kinesiologiae, 9(2), 89-104. https://doi.org/10.35469/ak.2018.171

Majeric, M. (2016). The importance of sport in students' lives and the frequency of sport participation among students - Gender differences. Sport Mont, 14(2), 3-6. http://www.sportmont.ucg.ac.me/?sekcija=article\&artid $=1337$

Martínez-Lemos, R. I., Puig Ribera, A., \& García-García, O. (2014). Perceived barriers to physical activity and related factors in Spanish university students. Open Journal of Preventive Medicine, 4(4), 164-174. https://doi.org/10.4236/ ojpm.2014.44022

Mertler, C. A. (2009), Teachers' assessment knowledge and their perceptions of the impact of classroom assessment professional development. Improving Schools, 12(2), 101-113. https://doi.org/10.1177/1365480209105575

Mleczko, E., \& Januszewski, J. (2009). Długookresowe tendencje przemian w rozwoju somatycznym i motorycznym krakowskich studentów [Long-term trends of changes in physical and motor development observed among Cracovian students]. Antropomotoryka, 19(46), 65-79.

Muszkieta, R., Napierała, M., Cieślicka, M., Żukov, W., Kozina, Z., lermakov, S., \& Górny, M. (2019). The professional attitudes of teachers of physical education. Journal of Physical Education and Sport, 19(Suppl. 1), 92-99. https://doi. org/10.7752/jpes.2019.s1014

National Association for Sport and Physical Education and American Heart Association. (2006). Shape of the nation report: Status of physical education in the USA. https://www.shapeamerica.org/advocacy/son/upload/ShapeOfTheNation-2006.pdf

Negasheva, M. A., \& Mishkova, T. A. (2005). Morphofunctional parameters and adaptation capabilities of students at the beginning of third millennium. Journal of Physiological Anthropology and Applied Human Science, 24(4), 397-402. https://doi.org/10.2114/jpa.24.397

Obama, M. (2012). The First Lady speaks out. Vibrant, 28(50), 32-30.

Podstawski, R. (2018). Physical education as an integral component of health education in higher schools. In A. Bodasińska, T. Jaślikowska-Sadowska, \& K. Piech, (Eds.), Dylematy szkolnego wychowania fizycznego. Różnorodność szansq na podniesienie atrakcyjności szkolnych i pozaszkolnych zajęć ruchowych (pp. 21-34). MCP Press.

Podstawski, R., Choszcz, D., Klimczak, D., Kolankowska, E., \& Żurek, P. (2014) Habits and attitudes of first-year female students at Warmia and Mazury University: A call for implementing health education programme at universities. Central European Journal of Public Health, 22(4), 143-146. https://doi. org/10.21101/cejph.a3975

Podstawski, R., Górnik, K., \& Gizińska, R. (2013). Habits and attitudes of first year students at Warmia \& Mazury University, Poland regarding healthy lifestyle. Education in Medicine Journal, 5(3), e64-e76. https://eduimed.usm.mv/ EIMJ20130503/EIMJ20130503 07.pdf

Podstawski, R., \& Sławek, M. (2016). The influence of political transformation in Poland on the functioning of the department of physical education and sport at the university of Warmia and Mazury in Olsztyn during the academic years of 1998/99 and 2010/2011. In B. Sokołowska (Ed.), Public health in the aspects of modern civilization (pp. 266-278). http://www.pswbp.pl/files/piotr szymczuk/ Barbara_Sokoowska.pdf 
Podstawski, R., Wesołowska, E., Gizińska R., \& Sołoma A. (2013). Health attitudes and behaviours of first-year University of Warmia and Mazury students: A call for implementing health education at universities. Problems in Education in the 21th Century, 54, 76-90. http://www.scientiasocialis.lt/pec/node/836

Sigmundová, D., Chmelík, F., Sigmund, E., Feltlová, D., \& Frömel, K. (2013). Physical activity in the lifestyle of Czech university students: Meeting health recommendations. European Journal of Sport Science, 13(6), 744-750. https://doi.org/ 10.1080/17461391.2013.776638

Shephard, R. J. (1997). Curricular physical activity and academic performance. Pediatric Exercise Science, 9(2), 113-126. https://doi.org/10.1123/pes.9.2.113

Thompson, W. R. (2017). Worldwide survey of fitness trends for 2018 ACSM's Health Fitness Journal, 21(6), 10-19. https://doi.org/10.1249/ FIT. 0000000000000341
Tomporowski, P. D. (2003). Cognitive and behavioral responses to acute exercise in youths: A review. Pediatric Exercise Science, 15(4), 348-359. https://doi. org/10.1123/pes.15.4.348

Varela-Mato, V., Cancela, J. M., Ayan, C., Martín, V., \& Molina, A. (2012). Lifestyle and health among Spanish university students: Differences by gender and academic discipline. International Journal of Environmental Research and Public Health, 9(8), 2728-2741. https://doi.org/10.3390/ijerph9082728

Valero, A., \& Van Reenen, J. (2019). The economic impact of universities: Evidence from across the globe. Economics of Education Review, 68, 53-67. https://doi.org/10.1016/i.econedurev.2018.09.001

Zhao, Y., Sigmund, E., Sigmundová, D., \& Lu, Y. (2007). Comparison of physical activity between Olomouc and Beijing university students using an International Physical Activity Questionnaire. Acta Universitatis Palackianae Olomucensis. Gymnica, 37(4), 107-114. https://gymnica.upol.cz/pdfs/gym/2007/04/14.pdf 